\title{
Geospallins A-C: New Thiodiketopiperazines with Inhibitory Activity against Angiotensin-Converting Enzyme from a Deep-Sea-Derived Fungus Geosmithia pallida FS140
}

\author{
Zhang-Hua Sun ${ }^{1,2,+}$, Jiangyong Gu ${ }^{3,+}$, Wei Ye ${ }^{1,+}{ }^{+}$, Liang-Xi Wen ${ }^{4}$, Qi-Bin Lin ${ }^{4}$, Sai-Ni Li ${ }^{1}$, \\ Yu-Chan Chen ${ }^{1}$, Hao-Hua Li $^{1}$ and Wei-Min Zhang ${ }^{1, * \mathbb{D}}$ \\ 1 State Key Laboratory of Applied Microbiology Southern China, Guangdong Provincial Key Laboratory of \\ Microbial Culture Collection and Application, Guangdong Open Laboratory of Applied Microbiology, \\ Guangdong Institute of Microbiology, Guangzhou 510070, China; sysuszh@126.com (Z.-H.S.); \\ yewei@gdim.cn (W.Y.); lisn@gdim.cn (S.-N.L.); yuchan2006@126.com (Y.-C.C.); hhli100@126.com (H.-H.L.) \\ 2 Guangdong Provincial Key Laboratory of New Drug, Development and Research of Chinese Medicine, \\ Mathematical Engineering Academy of Chinese Medicine, Guangzhou University of Chinese Medicine, \\ Guangzhou 510006, China \\ 3 The Second Institute of Clinical Medicine, Guangzhou University of Chinese Medicine, \\ Guangzhou 510006, China; gujy@gzucm.edu.cn \\ 4 School of Pharmaceutical Sciences, Guangzhou University of Chinese Medicine, Guangzhou 510006, China; \\ wen_en_liangxi@163.com (L.-X.W.); 15622154060@163.com (Q.-B.L.) \\ * Correspondence: wmzhang@gdim.cn; Tel.: +86-20-8768-8309 \\ + These authors contributed equally to this work.
}

Received: 23 October 2018; Accepted: 19 November 2018; Published: 23 November 2018

check for updates

\begin{abstract}
Three new thiodiketopiperazines, geospallins A-C (1-3), together with nine known analogues (4-12), were isolated from the culture of the deep-sea sediment-derived fungus Geosmithia pallida FS140. Among them, geospallins A and B (1 and 2) represent rare examples of thiodiketopiperazines featuring an S-methyl group at C-10 and a tertiary hydroxyl group at C-11. Their structures were determined by high-resolution electrospray mass spectrometry (HRESIMS), spectroscopic analyses, and electronic circular dichroism (ECD) calculations. Their angiotensin-converting enzyme (ACE) inhibitory activity was reported, and geospallins A-C (1-3) showed inhibitory activity with $\mathrm{IC}_{50}$ values of $29-35 \mu \mathrm{M}$.
\end{abstract}

Keywords: thiodiketopiperazines; Geosmithia pallida; deep-sea-derived fungus

\section{Introduction}

2,5-Diketopiperazines are cyclodipeptides obtained by the condensation of two $\alpha$-amino acids. This subunit is often found alone or embedded in larger, more complex architectures in a variety of natural products from fungi, bacteria, the plant kingdom, and mammals [1]. They are not only a class of naturally occurring privileged structures that have the ability to bind to a wide range of receptors, but they also have several characteristics that make them attractive scaffolds for drug discovery [2,3]. Thiodiketopiperazines, such as gliotoxins, chetoseminudins, luteoalbusins, chetracins, and apoaranotins, are common across the microbial world and have highly diverse organic structures characterized by sulfur-containing functional groups. They also exhibit various pharmacological activities, such as antifungal, antibacterial, and cytotoxic activities [4]. The angiotensin-converting enzyme (ACE) is an important target and has broad effects in different systems, and ACE inhibitors were originally developed for the treatment of congestive heart failure, diabetic kidney 
disease, and hypertension management [5]. ACE cleaves many peptides besides angiotensin I and thereby affects diverse physiological functions, including renal development and male reproduction. In addition, $\mathrm{ACE}$ has a role in both innate and adaptive responses by modulating macrophage and neutrophil function-effects that are magnified when these cells overexpress ACE. Macrophages that overexpress ACE are more effective against tumors and infections [5]. Sulfur-containing metabolites are crucial for the inhibitory activity against ACE, which catalyzes the reaction from angiotensin I to angiotensin II in the renin-angiotensin system and plays a major role in hypertension [6].

Recently, we initiated the investigation of microorganisms derived from deep-sea sediments, aiming at discovering new metabolites with potent bioactivity [7-9]. As part of the program, the fungus Geosmithia pallida FS140 was isolated from a sediment collected at a depth of $2403 \mathrm{~m}$ in the South China Sea $\left(19^{\circ} 28.581^{\prime} \mathrm{N}, 115^{\circ} 27.251^{\prime} \mathrm{E}\right)$. Chemical investigation of the fermentation broth led to the isolation of a series of diketopiperazines including three new thiodiketopiperazines, named geospallins A-C (1-3), as well as nine known analogues (4-12). Geospallins A and B (1 and 2) represent rare examples of thiodiketopiperazines featuring an S-methyl group at C-10 and a tertiary hydroxyl group at C-11. Biological tests verified that compounds 1-3 were responsible for the inhibition of ACE. Details of the isolation, structure elucidation, and biological activities of diketopiperazines 1-12 are presented below.

\section{Results}

The fermentation broth of the deep-sea-derived fungus G. pallida FS140 was extracted with EtOAc and then concentrated under reduced pressure to give an extract. The EtOAc extract was subjected to a series of solvent/solvent partitioning steps to afford compounds 1-12 (Figure 1). Three new structures were identified by the combination of spectroscopic analysis, high-resolution electrospray mass spectrometry (HRESIMS), and electronic circular dichroism (ECD) calculation, while twelve known analogues were identified as bisdethiobis (methylthio)gliotoxin (4) $[10,11]$, 6-acetylbis(methylthio)gliotoxin (5) [9,12], 6-deoxy-5a,6-didehydrogliotoxin (6) [13], 5a,6-didehydrogliotoxin (7) [14], 6-(phenylmethyl)-(3R,6R)-2,5-piperazinedione (8) [15], 3-(hydroxymethyl)-3,6-bis(methylthio)-6-(phenylmethyl)-(3R,6R)-2,5-piperazinedione (9) [15], 3-(hydroxymethyl)-6-(methoxyl)-6-(phenylmethyl)-(3R,6R)-2,5-piperazinedione (10) [16], 5a,6-anhydrobisdethiobis(methylthio)gliotoxin (11) [17], and bisdethiobis (methylthio)gliotoxin (12) [12] by comparison of their spectroscopic data with those in the literature.

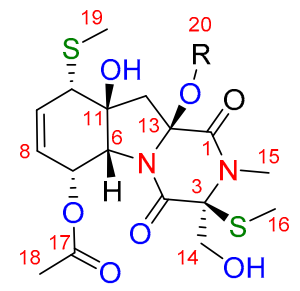

$1 \mathrm{R}=\mathrm{CH}_{3}$

$2 \mathrm{R}=\mathrm{H}$

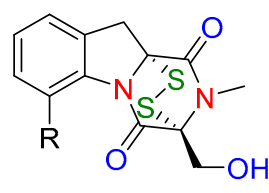

$6 \mathrm{R}=\mathrm{H}$

$7 \mathrm{R}=\mathrm{OH}$

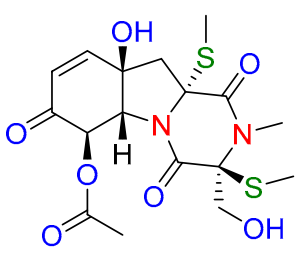

3

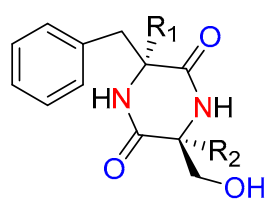

$8 \mathrm{R}_{1}=\mathrm{R}_{2}=\mathrm{H}$

$9 \quad \mathrm{R}_{1}=\mathrm{R}_{2}=\mathrm{SCH}_{3}$

$10 \mathrm{R}_{1}=\mathrm{OCH}_{3} \mathrm{R}_{2}=\mathrm{H}$

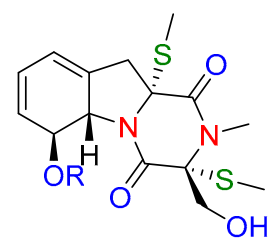

$4 \mathrm{R}=\mathrm{H}$

$5 \mathrm{R}=\mathrm{COCH}_{3}$

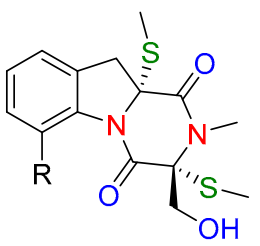

$11 \mathrm{R}=\mathrm{H}$

$12 \mathrm{R}=\mathrm{OH}$

Figure 1. Structures of compounds 1-12 isolated from G. pallida FS140. 


\subsection{Identification of New Compounds}

Compound 1, a colorless oil, had the molecular formula of $\mathrm{C}_{18} \mathrm{H}_{26} \mathrm{~N}_{2} \mathrm{O}_{7} \mathrm{~S}_{2}$, as determined by HRESIMS ( $\mathrm{m} / \mathrm{z} 469.1063[\mathrm{M}+\mathrm{Na}]^{+}$, calcd for 469.1074), corresponding to seven degrees of unsaturation. The ${ }^{1} \mathrm{H}$ NMR spectrum revealed the presence of five methyl singlets $\left(\delta_{\mathrm{H}} 3.15,2.99,2.26,2.05\right.$, and 1.76), a disubstituted double bond $\left(\delta_{\mathrm{H}} 6.00(2 \mathrm{H}, \mathrm{m})\right)$, and a series of aliphatic methylene or methine multiplets $(5.60(1 \mathrm{H}, \mathrm{s}), 5.52(1 \mathrm{H}, \mathrm{s}), 5.48(1 \mathrm{H}, \mathrm{d}, J=5.6 \mathrm{~Hz}), 4.23(1 \mathrm{H}, \mathrm{d}, J=1.8 \mathrm{~Hz}), 3.93(1 \mathrm{H}, \mathrm{dd}, J=11.7,6.7 \mathrm{~Hz})$, $3.68(1 \mathrm{H}, \mathrm{m}), 3.66(1 \mathrm{H}, \mathrm{m}), 2.54(1 \mathrm{H}, \mathrm{m})$, and $1.86(1 \mathrm{H}, \mathrm{d}, J=14.2 \mathrm{~Hz}))$. The ${ }^{13} \mathrm{C}$ NMR, in combination with HSQC experiments, resolved 18 carbon resonances attributed to three carbonyl groups $\left(\delta_{\mathrm{C}} 169.4\right.$, 167.6, and 163.5), a disubstituted double bond $\left(\delta_{\mathrm{C}} 137.2\right.$ and 127.4), three sp ${ }^{3}$ quaternary carbons $\left(\delta_{\mathrm{C}} 90.6,81.0\right.$, and 76.8$)$, three $\mathrm{sp}^{3}$ methines $\left(\delta_{\mathrm{C}} 70.5,65.2\right.$, and 51.8$)$, two sp ${ }^{3}$ methylene $\left(\delta_{\mathrm{C}} 62.8\right.$ and $42.3)$, a methoxyl group $\left(\delta_{C} 52.1\right)$, an $N$-methyl group $\left(\delta_{C} 28.6\right)$, and three methyl groups $\left(\delta_{C} 20.6,16.1\right.$, and 11.0) (Table 1). The 1D NMR data of 1 showed resonance characteristics of a thiodiketopiperazine framework similar to that of 5 , except for the absence of a double bond and presence of a methoxy group. In comparison with 5, the ${ }^{13} \mathrm{C}$ NMR spectroscopic data for $\mathbf{1}$ differed significantly from C-10 to $\mathrm{C}-13$, with the distinctly upfield-shifted carbon at C-13 ( $\delta_{\mathrm{C}} 90.6$ in 1 and $\delta_{\mathrm{C}} 75.2$ in 5) and the downfield-shifted at C-10 and C-11 ( $\delta_{C} 51.8$ and 81.0 in 1 and $\delta_{C} 120.5$ and 135.7 in 5, respectively). Detailed 2D NMR analyses $\left({ }^{1} \mathrm{H}_{-}{ }^{1} \mathrm{H}\right.$ COSY, HSQC, and HMBC) allowed the establishment of the gross structure of 1 as depicted in Figure 2. HMBC correlations from H-7 $\left(\delta_{\mathrm{H}} 5.48\right)$ and $\mathrm{H}_{3}-18\left(\delta_{\mathrm{H}} 2.05\right)$ to C-17 $\left(\delta_{\mathrm{C}} 169.4\right)$, from $\mathrm{H}_{3}-19\left(\delta_{\mathrm{H}} 2.26\right)$ to $\mathrm{C}-10\left(\delta_{\mathrm{C}} 51.8\right)$, and from OH-11 $\left(\delta_{\mathrm{H}} 5.60\right)$ to $\mathrm{C}-6 / \mathrm{C}-10 / \mathrm{C}-11 / \mathrm{C}-12$ $\left(\delta_{\mathrm{C}} 70.5,51.8,81.0\right.$, and 42.3 , respectively), and ${ }^{1}{ }^{\mathrm{H}}-{ }^{1} \mathrm{H}$ COSY correlations of $\mathrm{H}-6 / \mathrm{H}-7 / \mathrm{H}-8 / \mathrm{H}-9 / \mathrm{H}-10$ confirmed the presence of fragment A (Figure 2). Fragment B was very similar to 5, except for the distinct downfield-shifted of the O-methyl group when compared with the S-methyl group $\left(\delta_{\mathrm{C}} 52.1\right.$ in 1 and $\delta_{\mathrm{C}} 15.1 \mathrm{in}$ ). The methyl group was assigned to C-13 by the HMBC correlations from the methyl group $\left(\delta_{\mathrm{H}} 3.15\right)$ to the severely downfield-shifted C-13 (90.6 ppm in 1 and $75.2 \mathrm{ppm}$ in 5 , respectively).

The relative configuration of $\mathbf{1}$ was established on the basis of the interpretation of the NOESY data and ${ }^{1} \mathrm{H}-{ }^{1} \mathrm{H}$ coupling constants (Figure 2 and Table 1). The strong NOE interactions of $\mathrm{H}-10 / \mathrm{OH}-11$, $\mathrm{OH}-11 / \mathrm{H}-6, \mathrm{H}-6 / \mathrm{H}-7, \mathrm{OH}-11 / \mathrm{H}-12 \beta$, and $\mathrm{H}-12 \beta / \mathrm{H}_{3}-20$ indicated that $\mathrm{H}-10, \mathrm{OH}-11, \mathrm{H}-6, \mathrm{H}-7$, and $\mathrm{CH}_{3}-20$ occupied the axial bonds of the cyclohexane-ring portion in a chair conformation and were arbitrarily assigned $\beta$-orientations. Additionally, the axial orientation of both H-6 and H-7 were in good accordance with their small coupling constant of $1.8 \mathrm{~Hz}$.
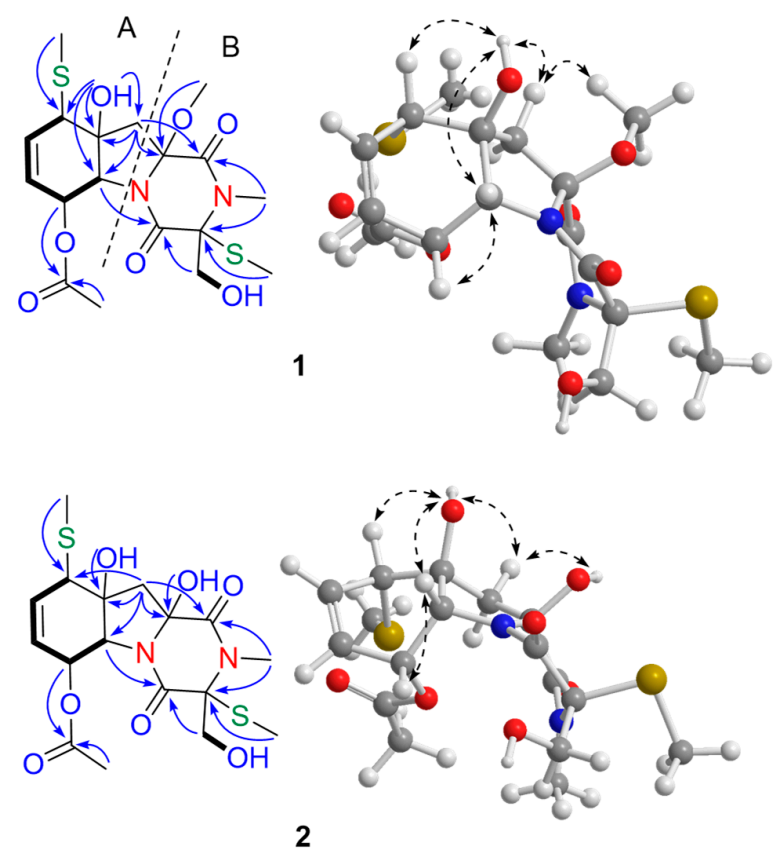

Figure 2. Key COSY (-), HMBC ( $\frown$ ), and NOESY $(\nleftarrow--)$ ) correlations for compounds 1 and 2. 
Table 1. ${ }^{1} \mathrm{H}(400 \mathrm{MHz})$ and ${ }^{13} \mathrm{C}(100 \mathrm{MHz})$ NMR data for compounds 1-3 (in DMSO- $\left.d_{6}\right)^{\mathrm{a}}$.

\begin{tabular}{|c|c|c|c|c|c|c|}
\hline \multirow{2}{*}{ No. } & \multicolumn{2}{|l|}{1} & \multicolumn{2}{|l|}{2} & \multicolumn{2}{|l|}{3} \\
\hline & ${ }^{1} \mathrm{H}$ & ${ }^{13} \mathrm{C}$ & ${ }^{1} \mathbf{H}$ & ${ }^{13} \mathrm{C}$ & ${ }^{1} \mathrm{H}$ & ${ }^{13} \mathrm{C}$ \\
\hline 1 & & 163.5 & & 166.1 & & 165.0 \\
\hline 3 & & 76.8 & & 77.9 & & 70.8 \\
\hline 4 & & 167.6 & & 167.6 & & 162.6 \\
\hline 6 & $4.23, \mathrm{~d}(1.8)$ & 70.5 & $4.32, \mathrm{~d}(1.8)$ & 70.5 & $4.96, \mathrm{~d}(11.0)$ & 69.8 \\
\hline 7 & $5.48, \mathrm{~d}(5.6)$ & 65.2 & $5.32, \mathrm{~d}(3.2)$ & 66.4 & $5.80, \mathrm{~d}(11.0)$ & 75.1 \\
\hline 8 & $6.00, \mathrm{~m}$ & 127.4 & $5.96, \mathrm{~d}(3.2)$ & 127.4 & & 191.6 \\
\hline 9 & $6.00, \mathrm{~m}$ & 137.2 & $5.96, \mathrm{~d}(3.2)$ & 137.2 & $6.09, \mathrm{~d}(10.3)$ & 125.4 \\
\hline 10 & $3.66, \mathrm{~m}$ & 51.8 & $3.65, \mathrm{~s}$ & 51.3 & $6.98, \mathrm{~d}(10.3)$ & 150.5 \\
\hline 11 & & 81.0 & & 81.4 & & 75.1 \\
\hline 12 & $\begin{array}{l}2.54, \mathrm{~m} \\
1.86, \mathrm{~d}(14.2)\end{array}$ & 42.3 & $\begin{array}{l}2.28, \mathrm{~d}(8.5) \\
2.12, \mathrm{~d}(14.2)\end{array}$ & 45.6 & $\begin{array}{l}\text { 3.07, d (14.9) } \\
2.95, \mathrm{~d}(14.9)\end{array}$ & 49.3 \\
\hline 13 & & 90.6 & & 86.3 & & 69.1 \\
\hline 14 & $\begin{array}{l}\text { 3.93, dd }(11.7,6.7) \\
3.68, \mathrm{~m}\end{array}$ & 62.8 & $\begin{array}{l}3.81, \mathrm{~m} \\
3.71, \mathrm{dd}(10.9,3.6)\end{array}$ & 62.2 & $\begin{array}{l}4.18, \text { dd }(11.5,6.0) \\
3.74, \text { dd }(11.5,4.7)\end{array}$ & 62.6 \\
\hline $\mathrm{N}-\mathrm{Me}$ & $2.99, \mathrm{~s}$ & 28.6 & $2.99, \mathrm{~s}$ & 29.1 & $2.99, \mathrm{~s}$ & 28.8 \\
\hline $\mathrm{SMe}-3$ & $1.76, \mathrm{~s}$ & 11.0 & $1.80, \mathrm{~d}(3.6)$ & 10.6 & $2.16, \mathrm{~s}$ & 13.0 \\
\hline OAc-7 & & 169.4 & & 169.4 & & 168.9 \\
\hline & $2.05, \mathrm{~s}$ & 20.6 & $2.05, \mathrm{~s}$ & 20.6 & $2.07, \mathrm{~s}$ & 20.4 \\
\hline SMe-10 & $2.26, \mathrm{~s}$ & 16.1 & $2.26, \mathrm{~s}$ & 16.1 & & \\
\hline OMe-13 & $3.15, \mathrm{~s}$ & 52.1 & & & $2.18, \mathrm{~s}$ & 14.6 \\
\hline $11-\mathrm{OH}$ & $5.60, \mathrm{~s}$ & & $5.68, \mathrm{~s}$ & & $6.00, \mathrm{~s}$ & \\
\hline $13-\mathrm{OH}$ & & & 6.04, brs & & & \\
\hline $14-\mathrm{OH}$ & $5.52, \mathrm{~s}$ & & 6.64, brs & & $5.34, \mathrm{t}(5.4)$ & \\
\hline
\end{tabular}

${ }^{a}$ Chemical shifts are in ppm; coupling constant $J$ is in $\mathrm{Hz}$.

In order to define the absolute configuration of $\mathbf{1}$, the ECD spectrum of $(3 R, 6 R, 7 R, 10 S, 11 R, 13 R)-\mathbf{1}$, $(3 R, 6 R, 7 R, 10 S, 11 R, 13 S)-\mathbf{1},(3 S, 6 S, 7 S, 10 R, 11 S, 13 R)-\mathbf{1}$, and (3S, 6S, 7S, 10R, 11S, 13S)-1 were calculated by the time-dependent density functional theory (TDDFT) computational method and compared with the experimental spectra of $\mathbf{1}$ (for details of calculations, see Supplementary Materials). The experimental ECD spectrum of 1 showed an ECD curve with positive Cotton effects around $219 \mathrm{~nm}$ (Figure 3a). The calculated ECD spectrum for (3S, 6S, 7S, 10R, 11S, 13S)-1 showed a similar ECD curve with positive Cotton effects at $220 \mathrm{~nm}$, indicating that 1 had an $(3 S, 6 S, 7 S, 10 R, 11 S, 13 S)$-configuration. Compound 1 was given the trivial name geospallin A.

The HRESIMS data of 2 exhibited a sodium adduct ion at $m / z 455.0907$ [M $+\mathrm{Na}]^{+}$(calcd 455.0917), consistent with the molecular formula $\mathrm{C}_{17} \mathrm{H}_{24} \mathrm{~N}_{2} \mathrm{O}_{7} \mathrm{~S}_{2} \mathrm{Na}$, showing 14 mass units less than that of 1 . The 1D NMR data of $\mathbf{2}$ were similar to those of $\mathbf{1}$, except for the absence of a methoxy group in $\mathbf{2}$, indicating 2 was a demethylated derivative of $\mathbf{1}$. The additional hydroxy group was located at C-13 by HMBC correlation from the hydroxyl group $\left(\delta_{\mathrm{H}} 6.04\right)$ to $\mathrm{C}-13\left(\delta_{\mathrm{C}} 86.3\right)$ (Figure 2$)$. The absolute configuration of $\mathbf{2}$ was confirmed by using the same methods as described for $\mathbf{1}$. The experimental ECD spectrum for 2 showed a similar ECD curve with positive Cotton effects at $220 \mathrm{~nm}$ (Figure S46 in Supplementary Materials), indicating that compound 2 has a $(3 S, 6 S, 7 S, 10 R, 11 S, 13 S)$-configuration. Compound 2 was given the trivial name geospallin $\mathrm{B}$.

Compound 3, a colorless oil, had the molecular formula of $\mathrm{C}_{17} \mathrm{H}_{22} \mathrm{~N}_{2} \mathrm{O}_{7} \mathrm{~S}_{2}$, as determined by HRESIMS ( $m / z 453.0764[\mathrm{M}+\mathrm{Na}]^{+}, \mathrm{C}_{17} \mathrm{H}_{22} \mathrm{~N}_{2} \mathrm{O}_{7} \mathrm{~S}_{2} \mathrm{Na}$, calcd for 453.0761), corresponding to eight degrees of unsaturation. The ${ }^{1} \mathrm{H}$ and ${ }^{13} \mathrm{C}$ NMR spectra (Table 1 ) of 3 showed high similarity to those of 5 , except for the presence of an $\alpha, \beta$-unsaturated ketone moiety $\left(\delta_{C} 191.6,125.4\right.$, and 150.5) in 3 instead of two double bonds in 5 , indicating that 3 was an oxidative derivative of 5 . This was supported by detailed 2D NMR spectra analyses (Figure 4). The location of the $\alpha, \beta$-unsaturated ketone moiety was assigned at $\mathrm{C}-11$ by HMBC correlations from $\mathrm{OH}-11\left(\delta_{\mathrm{H}} 6.00\right)$ to $\mathrm{C}-10, \mathrm{C}-11, \mathrm{C}-6$, and C-12 $\left(\delta_{\mathrm{C}} 150.5\right.$, $75.1,69.8$, and 49.3 , respectively); from $\mathrm{H}-10\left(\delta_{\mathrm{H}} 6.98\right)$ to C-6 and C-8 $\left(\delta_{\mathrm{C}} 191.6\right)$; and from H-7 $\left(\delta_{\mathrm{H}} 5.80\right)$ 
to the carbonyl group $\left(\delta_{\mathrm{C}} 191.6, \mathrm{C}-8\right)$ and acetyl group $\left(\delta_{\mathrm{C}} 168.9\right)$. The relative configuration of 3 was deduced by NOESY correlations of H-6/H-12 $\beta, \mathrm{H}-7 / \mathrm{H} 12 \alpha$, and H-12 $\alpha / \mathrm{SMe}-13$.

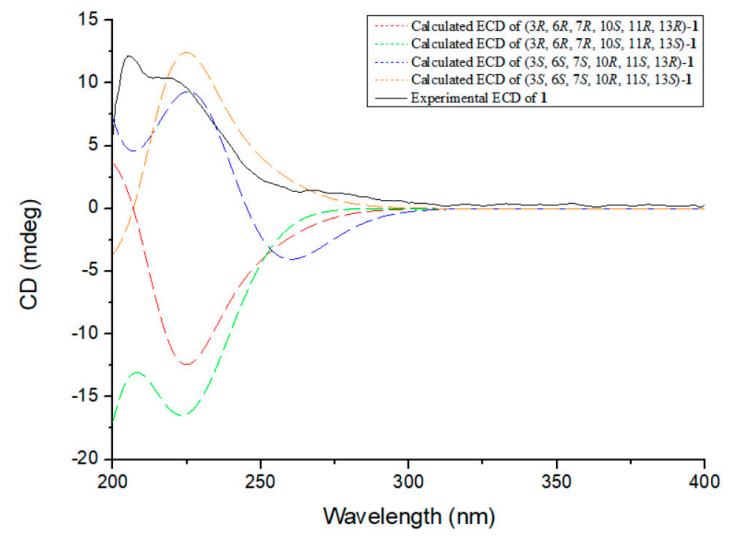

(a)

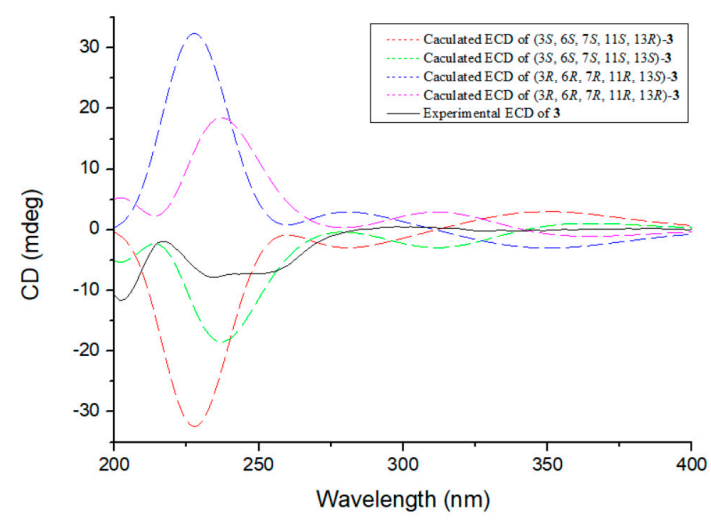

(b)

Figure 3. (a) Experimental electronic circular dichroism (ECD) spectra of geospallin A (1) in $\mathrm{MeOH}$ and calculated ECD spectra of $(3 R, 6 R, 7 R, 10 S, 11 R, 13 R)-1,(3 R, 6 R, 7 R, 10 S, 11 R, 13 S)-1,(3 S, 6 S, 7 S$, $10 R, 11 S, 13 R)-1$, and (3S, 6S, 7S, 10R, 11S, 13S)-1; (b) Experimental ECD spectra of geospallin C (3) in $\mathrm{MeOH}$ and calculated ECD spectra of $(3 S, 6 S, 7 S, 11 S, 13 R)-3,(3 S, 6 S, 7 S, 11 S, 13 S)-3,(3 R, 6 R, 7 R, 11 R$, $13 S)-3$, and $(3 R, 6 R, 7 R, 11 R, 13 R)-3$. The calculated ECD spectra were computed at the B3LYP/6-311G $(2 \mathrm{~d}+\mathrm{p})$ level.
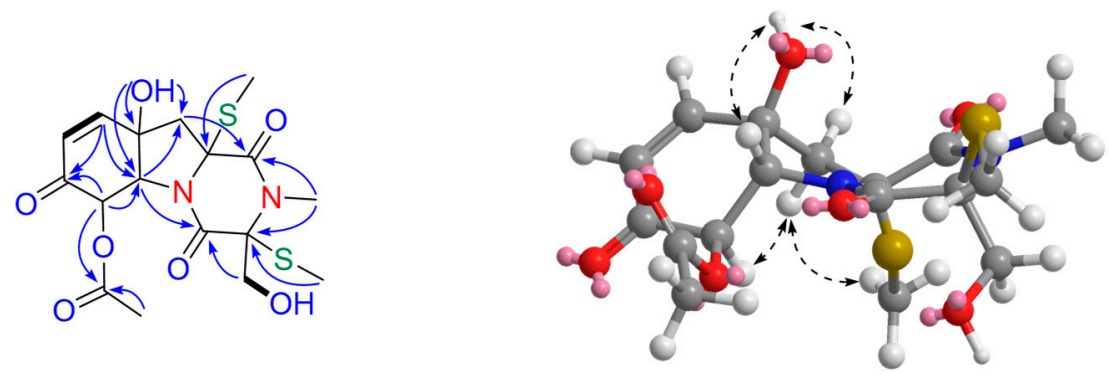

Figure 4. $\mathrm{Key}{ }^{1} \mathrm{H}_{-}{ }^{1} \mathrm{H}$ COSY $(-), \operatorname{HMBC}(\frown)$, and NOESY $(\leftarrow--)$ correlations for geospallin $\mathrm{C}(3)$.

The absolute structure of $\mathbf{3}$ was also deduced by comparison of the experimental and calculated ECD spectra generated by TDDFT calculations in the Gaussian 16 program (Figure 3b). As illustrated in Figure $3 b$, the experimentally acquired ECD spectrum for 3 agreed well with the ECD curve computed for $(3 S, 6 S, 7 S, 11 S, 13 S)-3$. Compound 3 was given the trivial name geospallin $C$.

\subsection{Angiotensin-Converting Enzyme (ACE) Inhibitory Assay}

The twelve thiodiketopiperazines (1-12) reported in this study were produced in sufficient amounts to allow testing for the inhibition of angiotensin-converting enzyme (Table 2). $\mathrm{IC}_{50}$ values above $100 \mu \mathrm{M}$ were not determined, while compounds $\mathbf{1}-\mathbf{3}$ showed inhibitory activity against ACE with an $\mathrm{IC}_{50}$ value range of $29-35 \mu \mathrm{M}$.

Table 2. $\mathrm{IC}_{50}$ values of compounds $\mathbf{1 - 3}$ against angiotensin-converting enzyme (ACE).

\begin{tabular}{cc}
\hline Compounds & $\mathrm{IC}_{\mathbf{5 0}}(\boldsymbol{\mu M})$ \\
\hline $\mathbf{1}$ & $35 \pm 5.2$ \\
$\mathbf{2}$ & $31 \pm 3.3$ \\
$\mathbf{3}$ & $29 \pm 3.3$ \\
Captopril & $0.041 \pm 0.005$ \\
\hline
\end{tabular}




\section{3. $\alpha$-Glucosidase Inhibitory Activity Assay}

All compounds were evaluated in vitro for $\alpha$-glucosidase inhibitory activity. However, none of the compounds showed inhibitory activity against $\alpha$-glucosidase at a concentration of $100 \mu \mathrm{M}$.

\section{Materials and Methods}

\subsection{General Experimental Procedures}

IR spectra were carried out on a Shimadzu IR Affinity-1 spectrophotometer (Shimadzu Corporation, Kyoto, Japan). UV data was acquired using a Shimadzu UV-2600 spectrophotometer (Shimadzu Corporation, Kyoto, Japan). Optical rotations were obtained on an Anton Paar MCP-500 (Anton Paar, Graz, Austria). Circular dichroism (CD) spectra were recorded on a Jasco 820 spectropolarimeter (Jasco Corporation, Kyoto, Japan). NMR spectra were determined on a Bruker Avance-400 spectrometer (Bruker Corporation, Fremont, CA, USA). ESI-MS spectra were measured on an Agilent Technologies 1290-6430A Triple Quad LC/MS (Agilent Technologies Inc., Santa Clara, CA, USA), and HRESIMS was measured on a Thermo MAT95XP high-resolution mass spectrometer (Thermo Fisher Scientific, Bremen, Germany). A Shimadzu LC-20 AP (Shimadzu Corporation, Kyoto, Japan) equipped with an SPD-M20A Photo-Diode Array (PDA) detector (Shimadzu Corporation, Kyoto, Japan) was used for HPLC analysis. A YMC-pack ODS-A column $(250 \times 20 \mathrm{~mm}, 5 \mu \mathrm{m}, 12 \mathrm{~nm}$, YMC CO., Ltd., Kyoto, Japan) was used for preparative HPLC separation. Column chromatography was conducted using a commercial silica gel $\left(\mathrm{SiO}_{2} ; 200-300\right.$ mesh; Qingdao Haiyang Chemical Co. Ltd., Qingdao, China) and Sephadex LH-20 gel (Amersham Biosciences, Uppsala, Sweden). All solvents were of analytical grade (Guangzhou Chemical Regents Company, Ltd., Guangzhou, China).

\subsection{Fungal Material and Identification}

The fungal strain FS140 was isolated from a deep-sea sludge in the South China Sea $\left(19^{\circ} 28.581^{\prime} \mathrm{N}\right.$, $115^{\circ} 27.251^{\prime}$ E, depth $2403 \mathrm{~m}$ ) in September 2011. The isolate was identified as Geosmithia pallida FS140 by sequence analysis of the internal transcribed spacer (ITS) region of the ribosomal DNA. The sequence data have been submitted to GenBank (accession no. MK047400), and FS140 has 99\% similarity with Geosmithia pallida CCF4279 (accession no. KF808303). The strain was deposited in the Guangdong Provincial Key Laboratory of Microbial Culture Collection and Application, Guangdong Institute of Microbiology, Guangzhou, People's Republic of China. Working stocks were prepared on potato dextrose agar (PDA) slants and stored at $4{ }^{\circ} \mathrm{C}$.

\subsection{Fermentation, Extraction, and Isolation}

Three pieces $\left(0.5 \times 0.5 \mathrm{~cm}^{2}\right)$ of mycelial agar plugs of G. pallida FS140 were inoculated into $250 \mathrm{~mL}$ of PD medium (potato $200 \mathrm{~g} / \mathrm{L}$, glucose $20 \mathrm{~g} / \mathrm{L}, \mathrm{KH}_{2} \mathrm{PO}_{4} 3 \mathrm{~g} / \mathrm{L}, \mathrm{MgSO}_{4} \cdot 7 \mathrm{H}_{2} \mathrm{O} 1.5 \mathrm{~g} / \mathrm{L}$, vitamin $\mathrm{B}_{1}$ $10 \mathrm{mg} / \mathrm{L}$, sea salt $15 \mathrm{~g} / \mathrm{L}$ ) in $500 \mathrm{~mL}$ Erlenmeyer flasks and incubated for 2 days in a rotary shaker $(200 \mathrm{r} / \mathrm{m})$ at $28^{\circ} \mathrm{C}$. The seed cultures $(10 \%)$ were then aseptically transferred into $500 \mathrm{~mL}$ of PD medium in $1000 \mathrm{~mL}$ Erlenmeyer flasks and kept shaking $(120 \mathrm{r} / \mathrm{m})$ at $28^{\circ} \mathrm{C}$ for 7 days. The whole fermentation broth $(80 \mathrm{~L})$ was filtered through cheese cloth to separate the supernatant from the mycelia. The supernatant was extracted with EtOAc $(4 \times 25 \mathrm{~L})$ and evaporated under reduced pressure to give a dark brown oily residue $(31 \mathrm{~g})$. The EtOAc-soluble fraction was separated over a column of silica gel and eluted with petroleum ether/EtOAc in a linear gradient $(30: 1 \rightarrow 1: 1)$ and followed by $\mathrm{CHCl}_{3} / \mathrm{MeOH}$ in linear gradient $(10: 1 \rightarrow 0: 1)$ to give 18 fractions (F1-F18). F7 was separated on a preparative reversed-phase (RP) HPLC system equipped with a C-18 column (YMC*GEL ODS-A, 120A S-5 $\mu \mathrm{m}, 250 \times 20 \mathrm{~mm}, \mathrm{MeOH} / \mathrm{H}_{2} \mathrm{O}, 0.1: 0.9 \rightarrow 1.0: 0,10 \mathrm{~mL} / \mathrm{min}$ ) to give 25 fractions (F7a-F7y). F7c was chromatographed over a Sephadex LH-20 column eluted with $\mathrm{CHCl}_{3} / \mathrm{MeOH}(1: 1, v / v)$, then further separated by preparative RP HPLC on the ODS-A column $\left(\mathrm{MeCN} / \mathrm{H}_{2} \mathrm{O}, 40: 60,10 \mathrm{~mL} / \mathrm{min}\right.$ ) to yield $2\left(4.5 \mathrm{mg}, t_{\mathrm{R}}=16.0 \mathrm{~min}\right), \mathbf{9}\left(23.0 \mathrm{mg}, t_{\mathrm{R}}=25.0 \mathrm{~min}\right), \mathbf{1 0}\left(6.1 \mathrm{mg}, t_{\mathrm{R}}=31.0 \mathrm{~min}\right)$, and 8 $\left(7.6 \mathrm{mg}, t_{\mathrm{R}}=34 \mathrm{~min}\right)$, sequentially. F7f was successfully separated by preparative RP HPLC on the 
ODS-A column $\left(\mathrm{MeCN} / \mathrm{H}_{2} \mathrm{O}, 45: 55,10 \mathrm{~mL} / \mathrm{min}\right)$ to afford $\mathbf{1}\left(5.9 \mathrm{mg}, t_{R}=12.1 \mathrm{~min}\right)$ and $3(6.8 \mathrm{mg}$, $t_{R}=13.4 \mathrm{~min}$ ). F7k was separated on a preparative RP HPLC on the ODS-A column (MeCN/ $\mathrm{H}_{2} \mathrm{O}, 50: 50$, $10 \mathrm{~mL} / \mathrm{min}$ ) to yield $4(427 \mathrm{mg})$, and $\mathrm{F} 7 \mathrm{~m}$ was purified by column chromatography on a Sephadex LH-20 $\left(\mathrm{CHCl}_{3} / \mathrm{MeOH}, 1: 1, v / v\right)$ to afford $5(312 \mathrm{mg})$. F9 was purified by preparative HPLC on the ODS-A column $\left(\mathrm{MeCN} / \mathrm{H}_{2} \mathrm{O}, 60: 40,10 \mathrm{~mL} / \mathrm{min}\right)$ to give $7\left(28 \mathrm{mg}, t_{\mathrm{R}}=14.2 \mathrm{~min}\right)$ and $12(16.8 \mathrm{mg}$, $t_{\mathrm{R}}=19.3 \mathrm{~min}$ ), while F10 was subjected to a Sephadex LH-20 column elution with $\mathrm{CHCl}_{3} / \mathrm{MeOH}(1: 1)$, then further separated by preparative HPLC on the ODS-A column $\left(\mathrm{MeCN} / \mathrm{H}_{2} \mathrm{O}, 65: 35,10 \mathrm{~mL} / \mathrm{min}\right)$ to obtain $6\left(39 \mathrm{mg}, t_{\mathrm{R}}=9.6 \mathrm{~min}\right)$ and $\mathbf{1 1}\left(18.1 \mathrm{mg}, t_{\mathrm{R}}=11.8 \mathrm{~min}\right)$, successively.

Geospallin A (1): colorless oil; $[\alpha]_{\mathrm{D}}^{25}+87.7$ (c 0.1, MeOH); CD (MeOH, c $\left.0.001 \mathrm{mg} / \mathrm{mL}\right) 219 \mathrm{~nm}$ $(\Delta \varepsilon+3.16)$; IR $v_{\max } 3443,2924,1739,1662,1372,1237,1095,1022 \mathrm{~cm}^{-1} ;{ }^{1} \mathrm{H}$ and ${ }^{13} \mathrm{C}$ NMR data, see Table 1; HRESIMS $m / z 469.1063\left([\mathrm{M}+\mathrm{Na}]^{+}\right.$, calcd for 469.1074).

Geospallin B (2): colorless oil; $[\alpha]_{\mathrm{D}}^{25}+84.9$ (c 0.1, MeOH); CD $(\mathrm{MeOH}, c 0.001 \mathrm{mg} / \mathrm{mL}) 225 \mathrm{~nm}$ $(\Delta \varepsilon+3.21) ; \mathrm{IR} v_{\max } 3315,3056,2923,1738,1667,1422,1373,1265,1236 \mathrm{~cm}^{-1} ;{ }^{1} \mathrm{H}$ and ${ }^{13} \mathrm{C}$ NMR data, see Table 1; HRESIMS $m / z 455.0907$ ([M + Na $]^{+}$, calcd for 455.0917).

Geospallin C (3): colorless oil; $[\alpha]_{\mathrm{D}}^{25}-28.2$ (c 0.1, MeOH); $\mathrm{CD}$ (MeOH, c $\left.0.001 \mathrm{mg} / \mathrm{mL}\right) 202(\Delta \varepsilon-3.52)$, $234(\Delta \varepsilon-2.36) \mathrm{nm} ; \mathrm{UV}(\mathrm{MeOH}) \lambda_{\max }(\log \varepsilon) 210$ (4.26) nm; IR $v_{\max } 3407,2925,1749,1703,1654,1415$, 1376, 1222, 1085, $1038 \mathrm{~cm}^{-1} ;{ }^{1} \mathrm{H}$ and ${ }^{13} \mathrm{C}$ NMR data, see Table 1 ; HRESIMS $\mathrm{m} / z$ 453.0764 $\left([\mathrm{M}+\mathrm{Na}]^{+}\right.$, calcd for 453.0761).

\subsection{Quantum Chemical ECD Calculation}

The quantum chemical ECD calculation methods were used to establish the absolute configurations of compounds 1-3. The 3D structures were generated by Discover Studio 2.5. The conformational search was performed by the Conformer Searching module of Open Babel 2.4.1 using a genetic algorithm and the MMFF94 molecular mechanics force field. The geometry optimizations were then performed by using density functional theory (DFT) at the b3lyp/6-311+g(2d,p) level. These stable conformers, which had no imaginary frequency, were subsequently submitted to ECD calculations by TDDFT calculations at the b3lyp/6-311+g(2d,p) level. The solvent effects were taken into account by the integral equation formalism polarizable continuum model (IEFPCM, methanol). All calculations were performed with the Gaussian 16 A.03 program [18]. The calculated spectra were drawn using SpecDis software with a UV shift to the ECD spectra.

\subsection{Angiotensin-Converting Enzyme (ACE) Inhibitory Assay}

ACE inhibitory activity was determined by a previously reported method [19]. In brief, $20 \mu \mathrm{L}$ thiodiketopiperazines dissolved in DMSO with different concentrations were added to $120 \mu \mathrm{L}$ N-hippuryl-His-Leu substrates, then preheated in water for 3-5 min; next, $10 \mu \mathrm{L}$ ACE enzymatic solution was added and mixtures were incubated at $37^{\circ} \mathrm{C}$ for $60 \mathrm{~min}$, and $150 \mu \mathrm{L} 1 \mathrm{M} \mathrm{HCl}$ was added to stop the reaction. The mixture was loaded for HPLC with a flow rate of $0.5 \mathrm{~mL} / \mathrm{min}$ by $60 \%$ methanol, and the absorbance at $228 \mathrm{~nm}$ was detected. To serve as a blank, $10 \mu \mathrm{L} \mathrm{pH} 8.3$ boric acid replaced the thiodiketopiperazines. Hippuric acid solutions at 10, 20, 40, 60, 80, and $100 \mu \mathrm{g} / \mathrm{mL}$ were prepared using $10 \mu \mathrm{L} \mathrm{pH} 8.3$ boric acid. One enzymatic unit was defined as the amount giving the production of $1 \mu \mathrm{M}$ hippuric acid by the catalyzation of the substrate N-hippuryl-His-Leu at $37^{\circ} \mathrm{C}$ in $1 \mathrm{~min}$. Captopril was used as a positive control. Physiological saline with a concentration of $0.9 \%(w / w)$ was used as a negative control in our experiment, which exhibited no inhibitory activity towards ACE. The $\mathrm{IC}_{50}$ values of thiodiketopiperazines were calculated after the ACE inhibitory experiments were conducted, using different concentrations of thiodiketopiperazines.

\section{6. $\alpha$-Glucosidase Inhibitory Activity Assay}

An assay of $\alpha$-glucosidase inhibitory activity was performed as previously described [20]. 


\section{Conclusions}

In this study, twelve diketopiperazines, including three new thiodiketopiperazines, were isolated from the deep-sea-derived fungus Geosmithia pallida. All the stereochemical configurations of the new compounds, including their absolute configurations, were established. Geospallins A and B (1 and 2) represent rare examples of thiodiketopiperazines featuring an S-methyl group at C-10 and a tertiary hydroxyl group at C-11, and their S-configuration at both C-7 and C-13 is the first report of such. These thiodiketopiperazines were examined for their angiotensin-converting enzyme inhibitory assay, and geospallins A-C (1-3) showed inhibitory activity, with $\mathrm{IC}_{50}$ values of $29-35 \mu \mathrm{M}$.

Supplementary Materials: The following are available online at http:/ /www.mdpi.com/1660-3397/16/12/464/s1, The ${ }^{1} \mathrm{H}$ - and ${ }^{13} \mathrm{C}-\mathrm{NMR}$ data of 1-12 and the HRESIMS and 2D-NMR spectra of compounds 1-3 (Figures S1-S47).

Author Contributions: Z.-H.S. fractionated the extract, isolated and elucidated structures, and wrote the paper; L.-X.W. and Q.-B.L. fractionated the extract and isolated a proportion of the compounds; J.G., performed the calculated ECD spectra experiment; S.-N.L. isolated and identified the fungal strain FS140; W.Y., Y.-C.C., and H.-H.L. performed the bioassays; W.-M.Z. designed and coordinated the study and reviewed the manuscript.

Funding: This work was supported financially by the Science and Technology Program of Guangzhou, China (201607020018), the Team Project of the Natural Science Foundation of Guangdong Province (2016A030312014), the National Natural Science Foundation of China (31272087), and the Guangdong Provincial Innovative Development of Marine Economy Regional Demonstration Projects (GD2012-D01-002).

Acknowledgments: The calculations were performed on the high-performance computer cluster of the Guangdong Provincial Hospital of Traditional Chinese Medicine.

Conflicts of Interest: The authors declare no conflict of interest.

\section{References}

1. Borthwick, A.D. 2,5-Diketopiperazines: Synthesis, reactions, medicinal chemistry, and bioactive natural products. Chem. Rev. 2012, 112, 3641-3716. [CrossRef]

2. Blunt, J.W.; Copp, B.R.; Keyzers, R.A.; Munro, M.H.G.; Prinsep, M.R. Marine natural products. Nat. Prod. Rep. 2016, 36, 382-431. [CrossRef] [PubMed]

3. Blunt, J.W.; Copp, B.R.; Munro, M.H.G.; Northcote, P.T.; Prinsep, M.R. Marine natural products. Nat. Prod. Rep. 2011, 28, 196-268. [CrossRef] [PubMed]

4. Huang, R.; Zhou, X.; Xu, T.; Yang, X.; Liu, Y. Diketopiperazines from marine organisms. Chem. Biodivers. 2010, 7, 2809-2829. [CrossRef] [PubMed]

5. $\quad$ Bernstein, K.E.; Khan, Z.; Giani, J.F.; Cao, D.Y.; Bernstein, E.A.; Shen, X.Z. Angiotensin-converting enzyme in innate and adaptive immunity. Nat. Rev. Nephrol. 2018, 14, 325-336. [CrossRef] [PubMed]

6. Nakabayashi, R.; Yang, Z.; Nishizawa, T.; Mori, T.; Saito, K. Top-down targeted metabolomics teveals a sulfur-containing metabolite with inhibitory activity against angiotensin-converting enzyme in Asparagus officinalis. J. Nat. Prod. 2015, 78, 1179-1183. [CrossRef] [PubMed]

7. Xu, J.L.; Liu, H.X.; Chen, Y.C.; Tan, H.B.; Guo, H.; Xu, L.Q.; Li, S.N.; Huang, Z.L.; Li, H.H.; Gao, X.X.; Zhang, W.M. Highly substituted benzophenone aldehydes and eremophilane derivatives from the deep-sea derived fungus Phomopsis lithocarpus FS508. Mar. Drugs 2018, 16, 329. [CrossRef] [PubMed]

8. Xu, J.; Tan, H.; Chen, Y.; Li, S.; Huang, Z.; Guo, H.; Li, H.; Gao, X.; Liu, H.; Zhang, M.W. Lithocarpins A-D: Four tenellone-macrolide conjugated [4 +2$]$ hetero-adducts from the deep-sea derived fungus Phomopsis lithocarpus FS508. Org. Chem. Front. 2018, 5, 1792-1797. [CrossRef]

9. Fan, Z.; Sun, Z.-H.; Liu, Z.; Chen, Y.-C.; Liu, H.-X.; Li, H.-H.; Zhang, W.M. Dichotocejpins A-C: New diketopiperazines from a deep-sea-derived fungus Dichotomomyces cejpii FS110. Mar. Drugs 2016, 14, 164. [CrossRef] [PubMed]

10. Gordon, W.K.; David, J.R.; Mark, A.S.; Ratnaker, R.T. Biosynthesis of bisdethiobis(methylthio)gliotoxin, a new metabolite of Gliocladium deliquescens. J. Chem. Soc. Perk. Trans. 1 1980, 1, 119-121. [CrossRef]

11. Afiyatullov, S.S.; Kalinovskii, A.I.; Pivkin, M.V.; Dmitrenok, P.S.; Kuznetsova, T.A. Alkaloids from the marine isolate of the fungus Aspergillus fumigatus. Chem. Nat. Compd. 2005, 41, 236-238. [CrossRef] 
12. Liang, W.L.; Le, X.; Li, H.J.; Yang, X.L.; Chen, J.X.; Xu, J.; Liu, H.L.; Wang, L.Y.; Wang, K.T.; Hu, K.C.; Yang, D.P.; Lan, W.J. Exploring the chemodiversity and biological activities of the secondary metabolites from the marine fungus Neosartorya pseudofischeri. Mar. Drugs 2014, 12, 5657-5676. [CrossRef] [PubMed]

13. Sun, Y.; Takada, K.; Takemoto, Y.; Yoshida, M.; Nogi, Y.; Okada, S.; Matsunaga, S. Gliotoxin analogues from a marine-derived fungus, Penicillium sp., and their cytotoxic and histone methyltransferase inhibitory activities. J. Nat. Prod. 2012, 75, 111-114. [CrossRef] [PubMed]

14. Forseth, R.R.; Fox, E.M.; Chung, D.; Howlett, B.J.; Keller, N.P.; Schroeder, F.C. Identification of cryptic products of the gliotoxin gene cluster using NMR-based comparative metabolomics and a model for gliotoxin biosynthesis. J. Am. Chem. Soc. 2011, 133, 9678-9681. [CrossRef] [PubMed]

15. Isaka, M.; Palasarn, S.; Rachtawee, P.; Vimuttipong, S.; Kongsaeree, P. Unique diketopiperazine dimers from the insect pathogenic fungus Verticillium hemipterigenum BCC 1449. Org. Lett. 2005, 7, 2257-2260. [CrossRef] [PubMed]

16. Zhao, W.Y.; Zhu, T.J.; Fan, G.T.; Liu, H.B.; Fang, Y.C.; Gu, Q.Q.; Zhu, W.M. Three new dioxopiperazine metabolites from a marine-derived fungus Aspergillus fumigatus Fres. Nat. Prod. Res. 2010, 24, 953-957. [CrossRef] [PubMed]

17. Harms, H.; Orlikova, B.; Ji, S.; Nesaei-Mosaferan, D.; König, G.M.; Diederich, M. Epipolythiodiketopiperazines from the marine derived fungus Dichotomomyces cejpii with NF-кB inhibitory potential. Mar. Drugs 2015, 13, 4949-4966. [CrossRef] [PubMed]

18. Frisch, M.J.; Trucks, G.W.; Schlegel, H.B.; Scuseria, G.E.; Robb, M.A.; Cheeseman, J.R.; Scalmani, G.; Barone, V.; Mennucci, B.; Petersson, G.A.; et al. Gaussian 16W, Revision A.03. Gaussian, Inc.: Wallingford, CT, USA, 2016.

19. Centeno, J.M.; Burguete, M.C.; Castelló-Ruiz, M.; Enrique, M.; Vallés, S.; Salom, J.B.; Torregrosa, G.; Marcos, J.F.; Alborch, E.; Manzanares, P. Lactoferricin-related peptides with inhibitory effects on ACE-dependent vasoconstriction. J. Agric. Food. Chem. 2006, 54, 5323-5329. [CrossRef] [PubMed]

20. Feng, J.; Yang, X.W.; Wang, R.F. Bio-assay guided isolation and identification of $\alpha$-glucosidase inhibitors from the leaves of Aquilaria sinensis. Phytochemistry 2011, 72, 242-247. [CrossRef] [PubMed]

(C) 2018 by the authors. Licensee MDPI, Basel, Switzerland. This article is an open access article distributed under the terms and conditions of the Creative Commons Attribution (CC BY) license (http:/ / creativecommons.org/licenses/by/4.0/). 